\title{
Development and evaluation of polyherbal formulation for memory enhancement: study on its antioxidant properties and synergistic effects
}

\author{
${ }^{1}$ Zainol Abidin, N.A., ${ }^{1,2, * K o r m i n, ~ F ., ~}{ }^{1}$ Mohamed Anuar, N.A.F. and ${ }^{1}$ Zainol Abidin, N.A. \\ ${ }^{1}$ Faculty of Applied Sciences and Technology, Universiti Tun Hussein Onn Malaysia, Hab Pendidikan \\ Tinggi Pagoh, KMM 1, Jalan Panchor, 84600 Panchor, Johor, Malaysia \\ ${ }^{2}$ Centre of Research for Sustainable Uses of Natural Resources (CoR-SUNR), Faculty of Applied Sciences \\ and Technology, Universiti Tun Hussein Onn Malaysia, Hab Pendidikan Tinggi Pagoh, KMM 1, Jalan \\ Panchor, 84600 Panchor, Johor, Malaysia
}

\begin{abstract}
Article history:
Received: 17 July 2019

Received in revised form: 10

September 2019

Accepted: 12 September 2019

Available Online: 26 October 2019
\end{abstract}

\section{Keywords:}

Total phenolic content,

Total flavonoid content,

DPPH,

FRAP assay,

ABTS assay

\section{DOI:}

https://doi.org/10.26656/fr.2017.4(2).258

\begin{abstract}
Centella asiatica, Piper sarmentosum and Morinda citrifolia is well-known for their memory enhancement contribution from traditional practices as well as recent researches. However, all three herbs are utilized individually and never mixed together. The nutrient data on the synergistic effect on all three herbs remain scarce. The aims of this research project were to apply Simplex-centroid mixture design in describing the study for the effect of polyherbal formulation on antioxidants properties and its synergistic effects. Based on results obtained, there was a significant difference in antioxidant properties of the polyherbal formulation. The results show the polyherbal formulation 3 and $13(M$. citrifolia only) has the highest antioxidant capacity when being tested with total phenolic content (TPC) (210.10 and $209.12 \mu \mathrm{g}$ GAE/mL respectively) and 2,2-diphenyl-1picrylhydrazyl (DPPH) (42.94 and 37.77\%) assays. Contradict to this result, the highest in total flavonoid content (TFC) and 2,2-azino-bis(3-ethylbenzothiazoline-6-sulphonic acid (ABTS) for describing antioxidant properties are formulations 1 and 11 (C. asiatica only). The TPC for formulation 1 and 11 are $479.8 \mu \mathrm{g} R E / m L$ and $470 \mu \mathrm{g} \mathrm{RE} / \mathrm{mL}$ respectively while ABTS radical inhibition for formulation 1 and 11 are $64.53 \%$ and $60 \%$ respectively. For ferric reducing ability of plasma (FRAP) assay, formulation $7(2.11 \mu \mathrm{g} \mathrm{FSE} / \mathrm{mL})$ is the highest which have 1:1:1 ratio of each herb. In addition, TPC, TFC, and DPPH assays showed high antioxidant activities when only single herbs were added into the formulation. Meanwhile, ABTS and FRAP are prone to binary polyherbal formulation. Hence, this study showed an antagonism effect instead of synergistic effect since single formulation exhibited the highest for TPC, TFC and DPPH. All tests gave the lowest antioxidant properties when the mix was ternary polyherbal formulation.
\end{abstract}

\section{Introduction}

A memory improving activity is due to the presence of antioxidant properties in medicinal plants. A variety of botanical products have been reported to possess memory improving activity. The consequences of this study indicate that extracts of polyherbal formulation in powder form (oven-dried) of $C$. asiatica, $P$. sarmentosum and $M$. citrifolia mix with honey from honeybee breed (Apis cerana) owns a synergistic effect towards benefiting cognitive performance (Kapoor et al., 2013; Zainol Abidin et al., 2018).

Most people prefer herbal nootropics over synthetic nootropics because they have fewer side effects. For instance, synthetic drugs possess morphine-like and hepatotoxicity effect (Zimmerman, 1999). Herbal plant mainly acts by different ways, for instance, by increasing and replenishing neurotransmitter at high concentration in brain, anti-depression, adaptogenic and mood stabilization, by improved oxygen supply and brain energy, stimulation and brain cell protection. These nootropics or herbal drugs are used by many in cognitive enhancement regimens. Hence important to use optimization technique to evaluate the polyherbal formulation product acceptability (Kapoor et al., 2013).

The traditional medicinal plants and functional foods are defined to have ingredients that have additional benefits over and above the normal plant (Exarchou et al., 2006). The antioxidant activity of these plants is a part of interest both because of their beneficial 
physiological activity on human cells as well as potential they must replace the synthetic antioxidants used in medicine and food (Repetto and Llesuy, 2002). Several types of anti-inflammatory, digestive, anti-necrotic, neuroprotective and hepatoprotective drugs have recently been shown to have an antioxidant and/or antiradical scavenging mechanism as part of their activity. In the search for new sources of natural antioxidants, medicinal plants have been extensively studied for their antioxidant and radical scavenging activity (Desmarchelier and Ciccia, 2000).

This research will be for the finding of $A$. cerana, $C$. asiatica, $P$. sarmentosum and $M$. citrifolia's antioxidant properties activity and memory improving effect as well as overall sensory acceptability (Lillrank, 2007; Martinez, 2010). This effect will surely facilitate the memory-boosting capacities and determine the acceptability in term of consuming them. In addition, the synergistic effect between all selected herbs that will be mixed together using honey will also be studied on. This research is the continuation of previous development and acceptance of polyherbal formulation for memory enhancement in term of sensory evaluation (Zainol Abidin et al., 2018).

\section{Materials and methods}

The herbals were purchased from Ethno Resources Sdn. Bhd., Sungai Buloh, Selangor, Malaysia. The raw herbs were collected from local villagers and natives in Kedah, Malaysia and supplied to Ethno Resources Sdn. Bhd. The collected herbs were oven-dried at $40^{\circ} \mathrm{C}$ for 5 days. The dried herbs were then ground into powder form. Pure honey from A. cerana was purchased from Madu Kira Haq Global Marketing Sdn. Bhd., Malacca. Folin-Cioclateu reagent, sodium carbonate, rutin, aluminium trichloride, DPPH (2,2-diphenyl-2picrylhydrazyl hydrate), 2,2-azinobis (3-ethylbenzothiazoline-6-sulfonic acid), acetate buffer, glacial acetic acid and TPTZ (2,4,6-tripyridyl-s-triazine) were purchased from Merck Germany. All the reagents were of analytical grade.

\subsection{Polyherbal preparation}

Three types of herbs from different families were selected for the polyherbal formulation. The part of powdered form herbs, $C$. asiatica, $P$. sarmentosum, $M$. citrifolia with respect to their high potential towards antioxidant properties which leads to memory enhancement was extracted and mixed with honey from honeybee (A. cerana). The formulations were as tabulated in Table 1. Polyherbal mix was extracted by decoction method where the temperature was set at $90^{\circ} \mathrm{C}$ for 10 mins and $10 \%$ concentration (10 g sample in 100
$\mathrm{mL}$ distilled water). The mixture was filtered via Whatman filter paper. About $5 \mathrm{~g}$ of honey was mixed with $1 \mathrm{~mL}$ filtrate of the polyherbal mix. These polyherbal mixtures were placed into small separate plastic packaging (polyethylene) in accordance with their desired ratio and the plastic was sealed with hot sealer.

\subsection{Antioxidants properties}

\subsubsection{Total phenolic content}

The content of total phenolic compounds in polyherbal was determined by Folin-Ciocalteu method (1927) with slight modification (Miliauskas et al., 2004). A calibration curve was constructed using gallic acid as standard. A total of $100 \mu \mathrm{L}$ of sample was mixed with 2 $\mathrm{mL}$ sodium carbonate $(2 \mathrm{~g}$ in $100 \mathrm{~mL}$ distilled water) and was left for 2 mins at room temperature. Then, it was mixed with Folin-Ciocalteu reagent and left for 30 mins. The experiment was done in triplicate. The absorbance reading was taken at $750 \mathrm{~nm}$. The absorbance values were compared to gallic acid standard curve (Miliauskas et al., 2004).

\subsubsection{Total flavonoid content}

The content of flavonoids was determined following the method by Sheehata et al. (2014) with few modifications using rutin as standard. An aliquot $(1 \mathrm{~mL})$ of the sample was mixed with $1 \mathrm{~mL}$ of $2 \%$ aluminium trichloride. The samples were left to incubate for 15 mins. The experiment was done in triplicate and the absorption was read at $430 \mathrm{~nm}$. Total contents of flavonoids were calculated by comparing the absorbance value against rutin standard (Sheehata et al., 2014).

\subsubsection{DPPH (2,2-diphenyl-2-picrylhydrazyl) assay}

This radical scavenging activity extract was measured following the method by Miliauskas et al. (2004) with minor modifications. The DPPH solution (5.9 mg in $100 \mathrm{~mL}$ methanol) was prepared fresh. $3 \mathrm{~mL}$ of DPPH solution was mixed with $77 \mu \mathrm{L}$ of sample in cuvettes. The mixed samples were kept in the dark for 15 mins at room temperature and the absorbance was read at $515 \mathrm{~nm}$. Gallic acid was used as standard curve. The experiment was done in triplicate. The radical scavenging activity was calculated using the following formula.

$$
\text { \%Inhibition }=[(\mathrm{AB}-\mathrm{AA}) / \mathrm{AB}] \mathrm{X} 100,
$$

Where $\mathrm{AB}$ is the absorption of blank sample at $\mathrm{t}=0 \mathrm{~min}$; and AA is the absorption of tested extract solution at $\mathrm{t}=$ 15 mins.

\subsubsection{ABTS (2,2-azinobis (3-ethyl-benzothiazoline-6-} sulfonic acid) assay 
For ABTS assay, the stock solution was prepared by dissolving the ABTS in water to $7 \mathrm{mmol}$ concentration. ABTS radical cation $\left(\mathrm{ABTS}^{+}\right)$was produced by reacting ABTS stock solution with $2.45 \mathrm{mmol}$ potassium persulfate (final concentration) and allowing the mixture to stand in the dark at room temperature for 12-16 hrs before usage. The solution was diluted by mixing $1 \mathrm{~mL}$ ABTS $^{+}$solution with $60 \mathrm{~mL}$ distilled water to obtain an absorbance of $0.70( \pm 0.02)$ at $734 \mathrm{~nm}$ using the spectrophotometer. A total of $200 \mu \mathrm{L}$ samples were allowed to react with $2000 \mu 1$ of the $\mathrm{ABTS}^{+}$solution for $2 \mathrm{hrs}$ in a dark condition. Absorbance reading was taken at $734 \mathrm{~nm}$. The experiment was done in triplicate. The percentage inhibition of absorbance was calculated and plotted as a function of concentration of antioxidants. The ascorbic acid standard curve was used to calibrate the values (Roberta et al., 1999; Sheehata et al., 2014)

\subsubsection{FRAP (Ferric Reducing Ability of Plasma) assay}

Reagents included $300 \mathrm{mmol} / \mathrm{L}$ acetate buffer with $\mathrm{pH} 3.6$, and $16 \mathrm{~mL}$ of glacial acetic acid; $10 \mathrm{mmol} / \mathrm{L}$ TPTZ (2,4,6-tripyridyl-s-triazine) in $40 \mathrm{mmol} / \mathrm{L} \mathrm{HCl}$; $20 \mathrm{mmol} / \mathrm{L} \mathrm{FeCl}_{3} \cdot 6 \mathrm{H}_{2} \mathrm{O}$. Working FRAP reagent was prepared as required by mixing $25 \mathrm{~mL}$ acetate buffer, 2.5 $\mathrm{mL}$ TPTZ solution and $2.5 \mathrm{~mL} \mathrm{FeCl}_{3} \cdot 6 \mathrm{H}_{2} \mathrm{O}$ solution. A total of $3 \mathrm{~mL}$ freshly prepared FRAP reagent was warmed to $37^{\circ} \mathrm{C}$ and a reagent blank reading was taken at $593 \mathrm{~nm}$. Sample of $100 \mu \mathrm{L}$ was then added along with $300 \mu \mathrm{L}$ distilled water. Absorbance reading was taken after 4 mins. The experiment was done in triplicate. The absorbance values were compared to ferrous sulphate standard curve (Benzie and Strain, 1996).

\subsubsection{Overall sensory evaluation}

All 10 formulations were tested on 50-trained panelists for its overall sensory acceptability (Zainol
Abidin et al., 2018).

\subsection{Simplex-centroid mixture design}

The mixture design of experiment was used to obtain the optimum composition between the polyherbal formulation for their antioxidant properties as well as overall sensory acceptance. Three components augmented simplex-centroid mixture design has been employed in which each component was studied in 6 types of responses which were TPC, TFC, DPPH, FRAP assay, ABTS assay and overall sensory acceptability. Design-Expert ${ }^{\circledR}$ Software Version 11.0 from State-ease Inc. was employed for experimental design, data analysis and model building (Scheffe, 1963).

\subsection{Calculation and statistics}

The statistical analysis was performed using DesignExpert ${ }^{\circledR}$ Software Version 11.0 from State-ease Inc. Values were performed as ANOVA, surface contours plot and triangular contour diagrams. The ANOVA was used to test for significant differences $(p<0.05)$ between the responses.

\section{Results and discussion}

\subsection{Experimental results}

The design layout and experimental results of antioxidant properties in terms of TPC, TFC, DPPH, ABTS assay and FRAP assay, as well as overall sensory acceptability as per the experimental results, were presented in Table 1.

\subsection{ANOVA analysis of antioxidant properties and overall acceptance}

Table 2 summarizes the ANOVA of the tests performed. The value of "Prob $>$ F" for responses TPC, TFC, DPPH, ABTS and FRAP are 0.0297, <0.0001,

Table 1. Design layout and experimental result for antioxidant properties and overall acceptance of sensory evaluation.

\begin{tabular}{|c|c|c|c|c|c|c|c|c|c|}
\hline \multirow{3}{*}{$\begin{array}{c}\text { Std run } \\
\text { no. }\end{array}$} & Factor & Factor & Factor & \multicolumn{6}{|c|}{ Response variables } \\
\hline & 1 & 2 & 3 & 1 & 2 & 3 & 4 & 5 & 6 \\
\hline & $\begin{array}{l}\text { C. asiatica } \\
(\% \mathrm{w} / \mathrm{v})\end{array}$ & $\begin{array}{c}\text { P. sarmentosum } \\
(\% \mathrm{w} / \mathrm{v})\end{array}$ & $\begin{array}{l}\text { M. citrifolia } \\
(\% \mathrm{w} / \mathrm{v})\end{array}$ & $\begin{array}{c}\text { TPC } \\
(\mathrm{g} / \mathrm{mL}) \text { in } \mathrm{GAE}\end{array}$ & $\begin{array}{c}\text { TFC } \\
(\mathrm{g} / \mathrm{mL}) \text { in } \mathrm{RE}\end{array}$ & $\begin{array}{c}\mathrm{DPPH} \\
(\%)\end{array}$ & $\begin{array}{c}\text { ABTS } \\
(\%)\end{array}$ & $\begin{array}{c}\text { FRAP } \\
(\%)\end{array}$ & $\begin{array}{c}\text { Overall } \\
\text { acceptance }\end{array}$ \\
\hline 1 & 1 & 0 & 0 & 134.33 & 479.8 & 34.92 & 64.533 & 1.19 & 7.12 \\
\hline 2 & 0 & 1 & 0 & 125.7 & 406.6 & 27.08 & 53.6747 & 1.79 & 6.46 \\
\hline 3 & 0 & 0 & 1 & 209.12 & 432.73 & 42.94 & 40.0664 & 1.26 & 5.78 \\
\hline 4 & 0.5 & 0.5 & 0 & 161.6 & 457.53 & 29.67 & 43.1958 & 0.9 & 6 \\
\hline 5 & 0.5 & 0 & 0.5 & 143.99 & 408.2 & 20.78 & 39.3551 & 1.69 & 6.54 \\
\hline 6 & 0 & 0.5 & 0.5 & 130.57 & 459.8 & 26.14 & 59.3646 & 1.62 & 6.32 \\
\hline 7 & 0.33 & 0.33 & 0.33 & 107.15 & 436.07 & 21.71 & 40.4457 & 2.11 & 6.34 \\
\hline 8 & 0.66 & 0.17 & 0.17 & 167.15 & 453.8 & 18.88 & 41.2518 & 1.55 & 6.36 \\
\hline 9 & 0.17 & 0.66 & 0.17 & 166.9 & 435.4 & 37.77 & 32.4798 & 1.5 & 6.48 \\
\hline 10 & 0.17 & 0.17 & 0.66 & 110.85 & 441 & 23.38 & 55.192 & 2.1 & 6.48 \\
\hline 11 & 1 & 0 & 0 & 133.33 & 470 & 30 & 60 & 1.2 & 6.98 \\
\hline 12 & 0 & 1 & 0 & 124.3 & 405 & 25 & 55 & 1.75 & 6.33 \\
\hline 13 & 0 & 0 & 1 & 210.1 & 433 & 42 & 45 & 1.3 & 5.5 \\
\hline 14 & 0.5 & 0.5 & 0 & 131.2 & 450 & 30 & 43 & 0.85 & 6.2 \\
\hline
\end{tabular}


Table 2. ANOVA Table of antioxidant properties (TPC, TFC, DPPH, ABTS and FRAP) and overall sensory acceptance

\begin{tabular}{|c|c|c|c|c|c|c|}
\hline \multirow{2}{*}{$\frac{\text { Response Variables }}{\text { TPC-Special quartic }}$} & \multirow{2}{*}{ Sum of square } & \multirow[t]{2}{*}{ Degree of freedom } & \multirow[t]{2}{*}{ Mean Square } & \multirow[t]{2}{*}{ F value } & \multicolumn{2}{|c|}{ Probability } \\
\hline & & & & & & \\
\hline Regression & 12354.36 & 8 & 1544.29 & 6.22 & 0.0297 & significant \\
\hline Residual & 1241 & 5 & 248.2 & & & \\
\hline Lack of fit & 776.96 & 1 & 776.96 & 6.7 & 0.0608 & not significant \\
\hline Pure error & 464.04 & 4 & 116.01 & & & \\
\hline Cor total & 13595.36 & 13 & & & & \\
\hline $\mathrm{R}^{2}$ & & & & & & 0.9087 \\
\hline $\operatorname{Adj} R^{2}$ & & & & & & 0.7627 \\
\hline Adeq Precisior & & & & & & 8.831 \\
\hline \multicolumn{7}{|l|}{ TFC-Quadratic } \\
\hline Regression & 6.743 .96 & 5 & 1348.79 & 50.09 & $<0.0001$ & significant \\
\hline Residual & 215.42 & 8 & 26.93 & & & \\
\hline Lack of fit & 137.73 & 4 & 34.43 & 1.77 & 0.2964 & not significant \\
\hline Pure error & 77.69 & 4 & 19.42 & & & \\
\hline Cor total & 6959.38 & 13 & & & & \\
\hline $\mathrm{R}^{2}$ & & & & & & 0.969 \\
\hline $\operatorname{Adj} R^{2}$ & & & & & & 0.9497 \\
\hline Adeq Precisior & & & & & & 20.869 \\
\hline \multicolumn{7}{|c|}{ DPPH-Special quartic } \\
\hline Regression & 739.66 & 8 & 92.46 & 23.9 & 0.0014 & significant \\
\hline Residual & 19.34 & 5 & 3.87 & & & \\
\hline Lack of fit & 4.58 & 1 & 4.58 & 1.24 & 1.24 & not significant \\
\hline Pure error & 14.76 & 4 & 3.69 & & & \\
\hline Cor total & 759.01 & 13 & & & & \\
\hline $\mathrm{R}^{2}$ & & & & & & 0.9745 \\
\hline $\operatorname{Adj} R^{2}$ & & & & & & 0.9337 \\
\hline Adeq Precisior & & & & & & 15.581 \\
\hline \multicolumn{7}{|c|}{ ABTS-Special quartic } \\
\hline Regression & 1188.78 & 8 & 148.6 & 25.75 & 0.0012 & significant \\
\hline Residual & 28.85 & 5 & 5.77 & & & \\
\hline Lack of fit & 5.51 & 1 & 5.51 & 0.94 & 0.3862 & not significant \\
\hline Pure error & 23.34 & 4 & 5.84 & & & \\
\hline Cor total & 1217.64 & 13 & & & & \\
\hline $\mathrm{R}^{2}$ & & & & & & 0.9763 \\
\hline Adj $R^{2}$ & & & & & & 0.9384 \\
\hline Adeq Precisior & & & & & & 14.906 \\
\hline \multicolumn{7}{|c|}{ FRAP-Special quartic } \\
\hline Regression & 1.99 & 8 & 0.25 & 245.66 & $<0.0001$ & significant \\
\hline Residual & 5.059 & 5 & 1.012 & & & \\
\hline Lack of fit & 2.279 & 1 & 2.278 & 3.28 & 0.1444 & not significant \\
\hline Pure error & 2.78 & 4 & 6.95 & & & \\
\hline Cor total & 1.99 & 13 & & & & \\
\hline $\mathrm{R}^{2}$ & & & & & & 0.9975 \\
\hline $\operatorname{Adj} \mathrm{R}^{2}$ & & & & & & 0.9934 \\
\hline Adeq Precisior & & & & & & 49.043 \\
\hline \multicolumn{7}{|c|}{ Overall acceptability-Quadratic [2] } \\
\hline Regression & 2.04 & 5 & 0.41 & 14.26 & 0.0008 & significant \\
\hline Residual & 0.23 & 8 & 0.029 & & & \\
\hline Lack of fit & 0.15 & 4 & 0.038 & 1.95 & 0.2667 & not significant \\
\hline Pure error & 0.077 & 4 & 0.019 & & & \\
\hline Cor total & 2.27 & 13 & & & & \\
\hline $\mathrm{R}^{2}$ & & & & & & 0.8991 \\
\hline $\operatorname{Adj} R^{2}$ & & & & & & 0.8361 \\
\hline Adeq precisior & & & & & & 12.074 \\
\hline
\end{tabular}


$0.0014,0.0012$ and $<0.0001$ respectively which are less than 0.05 .

The lack of fit for the dependent variables was insignificant. This is desirable, as we want a model that fits. The $\mathrm{R}^{2}$ value calculated for TPC, TFC, DPPH, ABTS and FRAP are 0.9087, 0.9690, 0.9745, 0.9763 and 0.9975 respectively, reasonably close to 1 , which is acceptable.

$\mathrm{R}^{2}$ value is the first criteria to see the appropriateness of the model from the determination coefficient. It can also reveal the total variation of the observed values of activity about its mean. It also implies that about more than $91 \%, 97 \%, 98 \%$ and $99.7 \%$ of the variability in the data are explained by the special quartic model (TPC, DPPH, ABTS and FRAP) while $97 \%$ by quadratic model (TFC).

The predicted $\mathrm{R}^{2}$ is in reasonable agreement with the adjusted $\mathrm{R}^{2}$. Adequate precision compares the range of the predicted values at the design points to the average prediction error. In this case, the value is well above 4 which indicate adequate model discrimination. ANOVA analysis of overall sensory acceptance was explained in the previous report (Zainol Abidin et al., 2018).

The following equation is the final empirical models in term of coded factors of TPC, TFC, DPPH, ABTS, FRAP and overall acceptability. Where, $\mathrm{CA}$ is $C$. asiatica; PS is P. sarmentosum; MC is M. citrifolia.

a) $\mathrm{TPC}=134.81 \mathrm{CA}+125.98 \mathrm{PS}+210.59 \mathrm{MC}+71.88$ $\mathrm{CA} * \mathrm{PS}-99.11 \mathrm{CA} * \mathrm{MC}-135.13 \mathrm{PS} * \mathrm{MC}+$ 21277.77CA2*PS*MC + 2901.77CA*PS2*MC 6181.70CA*PS*MC2

b) $\mathrm{TFC}=475.84 \mathrm{CA}+404.95 \mathrm{PS}+433.72 \mathrm{MC}+$ 51.47CA*PS - 176.71CA*MC + 157.12PS*MC

c) $\mathrm{DPPH}=32.54 \mathrm{CA}+26.12 \mathrm{PS}+42.55 \mathrm{MC}+$ 2.64CA*PS - 65.83CA*MC - 31.55PS*MC 780.80CA2*PS*MC $+1297.48 \mathrm{CA} * \mathrm{PS} 2 * \mathrm{MC}-$ 527.58CA*PS*MC2

d) $\mathrm{ABTS}=62.18 \mathrm{CA}+54.25 \mathrm{PS}+42.45 \mathrm{MC}-$ 61.15CA*PS - 53.17CA*MC + 42.72PS*MC 248.13CA2*PS*MC - 1630.40CA*PS2*MC + 1388.18CA*PS*MC2

e) $\quad$ FRAP $=1.19 \mathrm{CA}+1.77 \mathrm{PS}+1.28 \mathrm{MC}-2.44 \mathrm{CA} * \mathrm{PS}$ $+1.78 \mathrm{CA} * \mathrm{MC}+0.35 \mathrm{PS} * \mathrm{MC}+16.27 \mathrm{CA} 2 * \mathrm{PS} * \mathrm{MC}$ $-6.38 \mathrm{CA} * \mathrm{PS} 2 * \mathrm{MC}+46.63 \mathrm{CA} * \mathrm{PS} * \mathrm{MC} 2$

f) Overall acceptability $=7.01 \mathrm{CA}+6.41 \mathrm{PS}+5.67 \mathrm{MC}$ $-2.45 \mathrm{CA} * \mathrm{PS}+0.89 \mathrm{CA} * \mathrm{MC}+1.67 \mathrm{PS} * \mathrm{MC}[2]$

The equation in terms of coded factors can be used to make predictions about the response for given levels of each factor. By default, the high levels of the factors are coded as +1 and the low levels of the factors are coded as -1 . The coded equation is useful for identifying the relative impact of the factors by comparing the factor coefficients.

Examination of the fit summary output revealed that the special quartic model was statistically significant for the TPC, DPPH, ABTS, FRAP while the quadratic model was statistically significant for TFC and overall acceptance for sensory test. Therefore, this model was used to represent each of the response for further analysis. This can be observed from Table 2 where ANOVA Tables for both antioxidant properties and sensory evaluation were presented.

In order to ensure a good model, test for significance of the regression model, test for significance on individual model coefficients and test for lack of fit needed to be performed. An ANOVA Table for the response special quartic model for TPC, DPPH, ABTS and FRAP, quadratic model for TFC and overall acceptance on sensory evaluation were observed based on the value of F-ratio. The larger the magnitude of the $\mathrm{F}$ -value and the smaller the P-value, the more significant is the corresponding coefficient. The lack of fit can also be said to be insignificant.

The antioxidant properties vary considerably among herbs. The antioxidant properties of the polyherbal formulation were investigated using TPC, TFC, DPPH, ABTS and FRAP and the acceptance was determined by structured hedonic test. The reduction of ABTS and DPPH by antioxidants in the polyherbal are expressed as the percentage of radical scavenging activity and TPC, TFC and FRAP antioxidant capacity were ranked (from highest to lowest) as in Table 3.

The overall results indicate a strong association between antioxidative activities and phenolic compound, suggesting that phenolic compounds are probably responsible for the antioxidative activities of the herbs, C. asiatica, P. sarmentosum and M. citrifolia. A similar finding was reported that phenolic compounds are the major contributors to the antioxidative activity of apple, pineapple and vegetable juices (Gardner et al., 2000). It was also reported that phenolic compounds were responsible for the antioxidative activity in some selected fruits, vegetables and grains tested. Phenolic compounds are also effective hydrogen donors, which makes them good antioxidants (Rice-Evans et al., 1995; Velioglu et al., 1998).

Similarly, it was also reported that naturally occurring phenolics exhibit antioxidative activity. Thus, the antioxidant properties of polyherbal extracts may possibly be attributed to the phenolic compounds present. Although they are found to be the major 
Table 3. The ranking for the highest to lowest value; including polyherbal formulation

\begin{tabular}{cccccc}
\hline Rank/Values & $\begin{array}{c}\text { TPC } \\
(\mathrm{g} / \mathrm{mL}) \text { in }(\mathrm{GAE})\end{array}$ & $\begin{array}{c}\text { TFC } \\
(\mathrm{g} / \mathrm{mL}) \text { in }(\mathrm{RE})\end{array}$ & $\begin{array}{c}\text { DPPH } \\
(\% \text { scavenging effect })\end{array}$ & $\begin{array}{c}\text { ABTS } \\
(\% \text { scavenging effect })\end{array}$ & $\begin{array}{c}\text { FRAP } \\
(\mu \mathrm{mol} / \mathrm{g})\end{array}$ \\
\hline 1 & $3-209.12$ & $1-479.80$ & $3-42.94$ & $1-64.53$ & $7-2.11$ \\
2 & $8-167.15$ & $6-459.80$ & $9-37.77$ & $6-59.36$ & $10-2.10$ \\
3 & $9-166.90$ & $4-457.53$ & $1-34.92$ & $10-55.19$ & $2-1.79$ \\
4 & $4-161.60$ & $8-453.80$ & $4-29.67$ & $2-53.67$ & $5-1.70$ \\
5 & $5-143.99$ & $10-441.00$ & $2-27.08$ & $4-43.20$ & $6-1.62$ \\
6 & $1-134.33$ & $7-436.07$ & $6-26.14$ & $8-41.25$ & $8-1.55$ \\
7 & $6-130.57$ & $9-435.40$ & $10-23.38$ & $7-40.45$ & $9-1.50$ \\
8 & $2-125.70$ & $3-432.73$ & $7-21.71$ & $3-40.07$ & $3-1.26$ \\
9 & $10-110.85$ & $5-408.20$ & $5-20.78$ & $5-39.36$ & $1-1.20$ \\
10 & $7-107.15$ & $2-406.60$ & $8-18.88$ & $9-32.48$ & $4-0.90$ \\
\hline
\end{tabular}

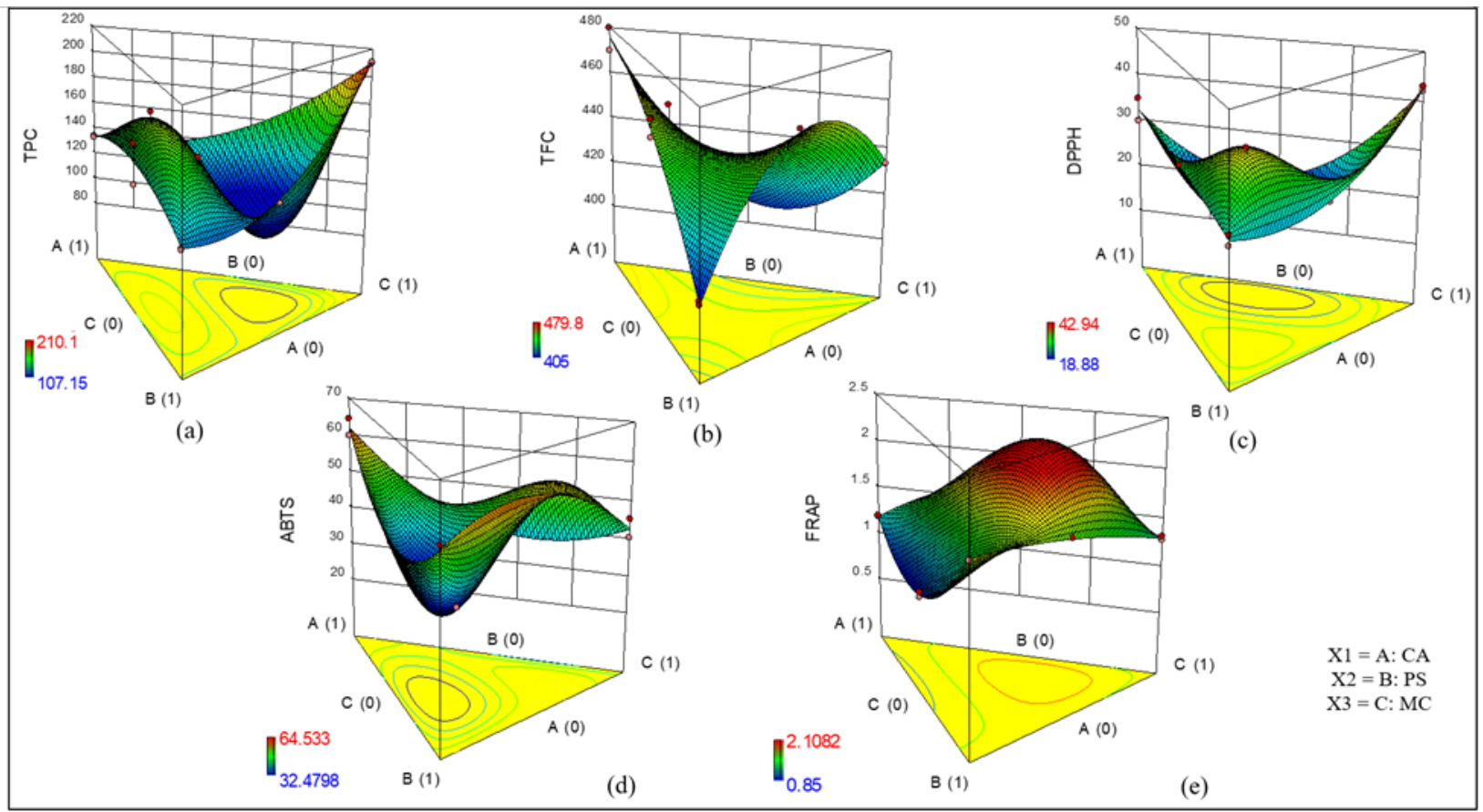

Figure 1. Surface plot of (a) TPC (b) TFC (c) DPPH (d) ABTS (e) FRAP

contributors to the antioxidative activity in $M$. citrifolia, $P$. sarmentosum and $C$. asiatica, the identity of these phenolic compounds remains unknown (Rice-Evans et al., 1995; Shahidi and Naczk, 1995; Velioglu et al., 1998; Granato et al., 2018).

\subsection{Surface contours plot and triangular-dimensional contours diagram}

The three-dimensional surface plots demonstrate the effect of different formulation on TPC, TFC, DPPH, ABTS and FRAP were depicted in Figure 1 (a), (b), (c), (d) and (e) respectively. Surface plots were then generated at each of the herbs $(C$. asiatica, $P$. sarmentosum and $M$. citrifolia) increased along the line from the centroid (1:1:1) toward its vertex (1:0:0) with honey as constant. The sensory acceptance's result was reported previously by Zainol Abidin et al. (2018). The contour plot is a two-dimensional (2D) representation of the response plotted against combinations of numeric factors and/or mixture components. It can show the relationship between the responses, mixture components and/or numeric factors (Rao and Baral, 2011). The mixture contour plots of the responses are depicted in Figure 2 to present more detailed interactions related to the regression models on the acceptance of polyherbal formulation. The diagrams illustrated three variations of interactions on the responses, in which the dark red areas represent the highest acceptance value. Meanwhile, green and blue indicate medium and the lowest acceptance value towards the response against the factors.

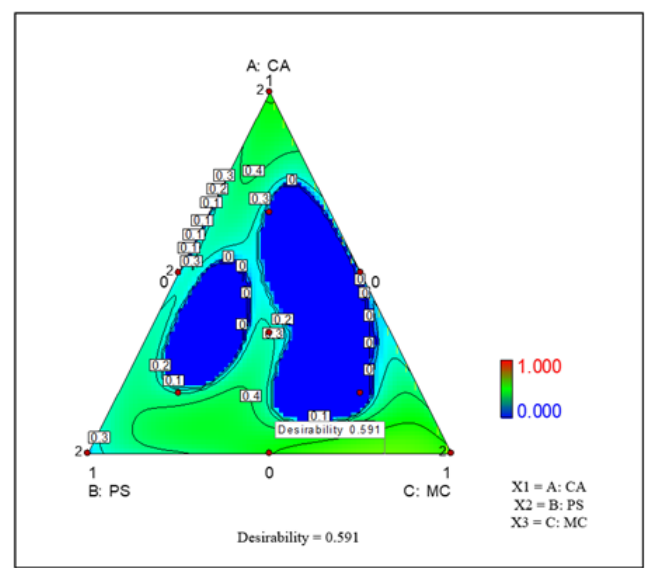

Figure 2. Desirability and optimisation of antioxidant properties

(C) 2019 The Authors. Published by Rynnye Lyan Resources 
3.4 Optimised polyherbal mix by simplex-centroid mixture design: antioxidant properties and overall sensory acceptance

Optimization of the levels to get best combination was resolved through graphical optimisation procedure of design expert software by giving criteria to maximise the TPC, TFC, DPPH, ABTS and FRAP as shown in Figure 2. Higher desirability value or the value closer to 1 indicates how best the criteria given for optimization are meeting.

The desirability value of this design is 0.591 which indicates medium met of optimisation criteria. Responses with no goal are often shown with gray, but in this study, none was found. The optimised formulation is when $0 \%$ C. asiatica; $18.5 \%$ P. sarmentosum $; 81.5 \%$ M. citrifolia was applied as the formulation for the polyherbal. There is a total of five optimised solutions with desirability value ranging from 0.344 to 0.591 as shown in Table 4 .

Table 4. The Desirability with optimised proportions factors

\begin{tabular}{ccccc}
\hline \multirow{2}{*}{ Rank } & \multirow{2}{*}{ Desirability } & \multicolumn{4}{c}{ Factors (\%) } \\
\cline { 3 - 5 } & & C. asiatica & P. sarmentosum & M. citrifolia \\
\hline 1 & 0.591 & 0 & 18.5 & 81.5 \\
2 & 0.526 & 0 & 0 & 1 \\
3 & 0.516 & 100 & 0 & 0 \\
4 & 0.463 & 6.85 & 63.8 & 29.35 \\
5 & 0.344 & 20.04 & 79.96 & 0 \\
\hline
\end{tabular}

The optimum overall acceptance of polyherbal mix was determined through the highest mean obtained from the overall acceptance response in sensory evaluation. It can be observed that the highest mean score 7.00 followed by 6.98 and 6.74 were obtained from formulation 11, 1 and 8 respectively. The most preferred polyherbal formulation as the best proportion of these components is the one containing C. asiatica only. This can be supported by previous research done where optimisation of the polyherbal formulation results shown $96.04 \%$ C. asiatica; $0 \%$ P. sarmentosum; $3.96 \% M$. citrifolia of the herbal concentration where the desirability value indicates high criteria $(0.822)$. The formulation with only $C$. asiatica only also obtained the highest mean score (Zainol Abidin et al., 2018).

3.5 Effect of single, binary and ternary polyherbal formulation on antioxidant properties and overall sensory acceptance

Table 5 indicates the average of TPC, TFC, DPPH,
ABTS and FRAP in different polyherbal formulation which the formulations were for single; honey mixed with single herbs, binary; honey mixed with two kind of herbs while ternary; honey mixed with three types of herbs. TPC, TFC, and DPPH assays showed high antioxidant activities when only single herbs were added into the formulation. Meanwhile, ABTS and FRAP are prone to binary polyherbal formulation. It is reported that herbal combination often produces a promising effect in treatment of diseases over a single drug (Ramaiah et al., 2013).

Naturally occurring herbs and herbal ingredients organized into certain formula have been shown to have potential interaction effects. These include mutual enhancement, mutual assistance, mutual restraint and even mutual antagonism (Ramaiah et al., 2013). Hence, in this study, the results showed an antagonism effect instead of synergistic effect since single formulation exhibited the highest for TPC, TFC and DPPH. All tests gave the lowest antioxidant properties when the mix was ternary polyherbal formulation. Since there is limited research on the synergistic effect on exact herbs $C$. asiatica, $P$. sarmentosum and $M$. citrifolia, solid evidence to support this statement is limited. For sensory evaluation, panelists prefer binary formulation compared to single and ternary. Previously stated that the most preferred polyherbal formulation is the one containing $C$. asiatica only. M. citrifolia single polyherbal formulation is the least preferred among single formulation and even among the binary formulation when it is mixed with $P$. sarmentosum. But when M. citrifolia was mixed with $C$. asiatica, the overall acceptability increased. Hence, it can be concluded that $C$. asiatica was able to mask the unacceptability of the other two herbs while by itself is the most preferred (Zainol Abidin et al., 2018).

\subsection{Relationship between antioxidant properties and memory enhancement}

Acetylcholinesterase, the major cholinesterases in human blood, muscle and brain cells, which primarily hydrolases acetylcholine (Matinez, 2010). This neurotransmitter has been shown to be important for memory, attention and learning. Acetylcholine has functions both in the peripheral nervous system (PNS) and in the central nervous system (CNS) as a neuromodulator. In the peripheral nervous system, acetylcholine activates muscles and is a major neurotransmitter in the autonomic nervous system

Table 5. Average of TPC, TFC, DPPH, ABTS, FRAP in different polyherbal formulation

\begin{tabular}{ccccccc}
\hline $\begin{array}{c}\text { Polyherbal } \\
\text { formulation }\end{array}$ & $\begin{array}{c}\text { TPC } \\
(\mathrm{g} / \mathrm{mL}) \text { in }(\mathrm{GAE})\end{array}$ & $\begin{array}{c}\text { TFC } \\
(\mathrm{g} / \mathrm{mL}) \text { in }(\mathrm{RE})\end{array}$ & $\begin{array}{c}\text { DPPH } \\
(\% \text { scavenging effect })\end{array}$ & $\begin{array}{c}\text { ABTS } \\
(\% \text { scavenging effect })\end{array}$ & $\begin{array}{c}\text { FRAP } \\
(\mu \mathrm{mol} / \mathrm{g})\end{array}$ & $\begin{array}{c}\text { Overall sensory } \\
\text { acceptance }\end{array}$ \\
\hline Single & 156.1467 & 33.6567 & 53.04568 & 437.855 & 1.415428 & 6.3617 \\
Binary & 141.84 & 26.6475 & 46.22888 & 443.8825 & 1.264328 & 7.765 \\
Ternary & 138.0125 & 25.435 & 42.34233 & 441.5675 & 1.814915 & 6.415 \\
\hline
\end{tabular}


(Ullrank, 2007). According to previous studies, chronic treatment with antioxidant present in berberine significantly decreased the cholinesterase enzyme activity in the cortex of lab rat (Bhutadaa et al., 2011). In addition, studies on oxidative damage and claimed that oxidation was considered a likely cause of ageassociated brain dysfunction because the brain is believed to be particularly vulnerable to oxidative stress due to a relatively high rate of oxygen free radical generation without commensurate levels of antioxidative defenses (Raghavendra and Kulkarnia, 2001).

Since amnesia associated with increased brain oxidative stress during brain aging or other brain stress, it can be reversed by antioxidants. Cognitive deficits such as learning impairment and delayed amnesia are the debilitating consequences of aging (Cao et al., 1997). The age-associated impairment of cognitive and motor functions has been hypothesized as due to oxidative molecular damage. Antioxidant protected the brain cells against increased oxidative stress-induced during aging or by other chronic treatment (Raghavendra and Kulkarnia, 2001). It can also remove free radical production and/or intercept dissemination of autoxidation (Taslimi and Gulcin, 2018). Therefore, high antioxidant properties of a polyherbal formulation can help in memory enhancement.

\subsection{Relationship between antioxidant properties and overall sensory acceptance}

Optimization for sensory evaluation suggested a polyherbal formulation containing $C$. asiatica only as of the best proportion of these components. Meanwhile, the optimised polyherbal formulation for the highest antioxidant properties is when $0 \%$ C asiatica; $18.5 \% P$. sarmentosum; $81.5 \%$ M. citrifolia was applied. The result for antioxidant properties and sensory evaluation contradict one another. While the consumers will prefer C. asiatica only, we can provide better formulation to increase the antioxidant properties. Hence, we had concluded for the product development evolution, in vision of health-conscious society with little care about the taste, the formulation with $0 \% C$. asiatica; $18.5 \% P$. sarmentosum; $81.5 \%$ M. citrifolia is the ideal as the highest antioxidant properties. Likewise, for the society who prefer taste over health, the formulation with only C. asiatica is ideal. But, in order to optimise the antioxidant properties to tally with the overall acceptance of the product, further research needs to be done to come out with an ultimate formulation to mask the unacceptable sensory attributes.

\section{Conclusion}

Simplex-centroid mixture design was determined for antioxidant properties (TPC, TFC, DPPH, ABTS and FRAP) and sensory evaluation for the development and evaluation of polyherbal formulation. The results obtained that the formulation 3 and 13 which are the repetition of formulation with $M$. citrifolia only has the highest antioxidant capacity when being tested with TPC (210.10 and 209.12 $\mu \mathrm{g}$ GAE/mL respectively) and DPPH (42.94 and $37.77 \%$ inhibition) assays. Contradict to this result, the highest TFC and ABTS antioxidant properties are formulations 1 and 11 which are the repetitive formulation of $C$. asiatica only. The TPC for formulation 1 and 11 are $479.8 \mu \mathrm{g} R E / \mathrm{mL}$ and $470 \mu \mathrm{g} R E / \mathrm{mL}$ respectively) while ABTS radical inhibition for formulation 1 and 11 are $64.53 \%$ and $60 \%$ respectively. For FRAP assay, the highest antioxidant activity is formulation $7(2.11 \mu \mathrm{g} \mathrm{FSE} / \mathrm{mL})$ which have 1:1:1 ratio of each herbal concentration. In addition, TPC, TFC, and DPPH assays showed high antioxidant activities when only single herbs were added into the formulation. Meanwhile, ABTS and FRAP are prone to binary polyherbal formulation. Hence, in this study the results showed an antagonistic effect instead of synergistic effect since single formulation exhibited the highest for TPC, TFC and DPPH. All tests gave the lowest antioxidant properties when the mix were ternary polyherbal formulation. Hence, through all the results obtained, SCMD had optimised the polyherbal formulation to come up with the highest antioxidant properties formulation. The most preferred is the one containing $0 \% C$. asiatica; $18.5 \% \quad P$. sarmentosum; $81.5 \%$ M. citrifolia in the polyherbal formulation. In the aspect of sensory evaluation, the most preferred polyherbal formulation as the best proportion of these components is the one containing $C$. asiatica only.

\section{Conflict of Interest}

Authors declare no conflict of interest.

\section{Acknowledgments}

Financial support from Office of Innovation, Commercialization and Consultancy Management (ICC) through the Tier1 funding vote no. H256 and GPPS funding vote no. H052 provided by Universiti Tun Hussein Onn Malaysia (UTHM) in assistance with the Malaysian Government is gratefully acknowledged. This research was also supported in part of Fundamental Research Grant Scheme, Ministry of Higher Education, Malaysia (FRGS)RMK 10/11.

\section{References}

Benzie, I.F. and Strain, J. (1996). The ferric reducing ability of plasma (FRAP) as a measure of 
"antioxidant power": the FRAP assay. Analytical Biochemistry, 239(1), 70-76. https://doi.org/10.1006/ abio.1996.0292

Bhutadaa, P., Mundhadaa, Y., Bansd, K., Tawaria, S., Patila, S., Dixitb, P. and Mundhadaa, D. (2011). Protection of cholinergic memory dysfunction in rat model of streptozotocin in induced diabetes. Behavioural Brain Research, 220(1), 30-41. https:// doi.org/10.1016/j.bbr.2011.01.022

Cao, G., Sofic, E. and Prior, R.L. (1997). Antioxidant and prooxidant behavior of flavonoids; Structure activity relationships. Free Radical Biology and Medicine, 22(5), 749-760. https://doi.org/10.1016/ S0891-5849(96)00351-6

Desmarchelier, C. and Ciccia, G. (2000). microencapsulation of Morinda citrifolia L. extract by spray drying. Chemical Engineering Research and Design, 90(5), 622-632. https://doi.org/10.1016/ j.cherd.2011.09.003

Exarchou, P.T., Fiamegos, Y.C., van Beek, T.A., Nanos, C. and Vevoort, J. (2006). Hyphenated chromatographic techniques for the rapid screening and identification of antioxidants in methanlic extracts of pharmaceutically used plants. Journal of Chromatography A, 1112(1-2), 293-302. https:// doi.org/10.1016/j.chroma.2005.11.077

Gardner, P.T., White, T.A., McPhail, D.B. and Duthie, G.G. (2000). The relative contributions of vitamin c, carotenoids and phenolics to the antioxidant potential of fruit juices. Food Chemistry, 68(4), 471474. https://doi.org/10.1016/S0308-8146(99)00225-3

Granato, D., Shahidi, F., Wrolstad, R., Kilmartin, P., Melton, L.D., Hidalgo, F.J., Miyashita, K., van Camp, J., Alasalvar, C., Ismail, A.B., Elmore, S., Birch, G.G., Charalampopoulos, D., Astley, S.B., Pegg, R., Zhou P. and Finglas, P. (2018). Antioxidant activity, total phebolics and flavonoids contents: should we ban in vitro screening methods. Food Chemistry, 264, 471-475. https:// doi.org/10.1016/j.foodchem.2018.04.012

Kapoor, D, Vyas, R.B., Lad, C. and Patel, M. (2013) Enrichment of memory by using herbal formulations. Journal of Drug Delivery and Therapeutics, 3(5), 163-171. https://doi.org/10.22270/jddt.v3i5.638

Lillrank, S.M. (2007). Alzheimer's Disease and Other Dementias. New York: Infobase Publishing.

Matinez, A. (2010). Emerging Drugs and Targets for Alzheimer's disease: Vol. 1, London: RSC Publishing.

Miliauskas, G., Venskutonis, P.R. and Van Beek, T.A. (2004). Screening of radical scavenging activity of some medicinal and aromatic plant extracts. Food
Chemistry, 85(2), 231-237. https://doi.org/10.1016/ j.foodchem.2003.05.007

Raghavendra, V. and Kulkarnia, S.K. (2001). Possible antioxidant mechanism in elatonin reversal of aging and chronic ethanol-induced amnesia in plus-maze and passsive avoidance memory tasks. Free Radical Biology and Medicine, 30(6), 595-602. https:// doi.org/10.1016/S0891-5849(00)00447-0

Ramaiah, M., Chakravathi, G. and Yasaswini, K. (2013). In vitro biological standardization, formulation and evaluation of directly compressed polyherbal anthelmintic tablets. Pharmacognosy Journal, 5(3), 124-130. https://doi.org/10.1016/j.phcgj.2013.04.004

Rao, P.V. and Baral, S.S. (2011). Experimental design of mixture for the anaerobic co-digestion of sewage sludge. Chemical Engineering Journal, 172(2-3), 977-986. https://doi.org/10.1016/j.cej.2011.07.010

Repetto, M. and Llesuy, S. (2002). Antioxidant properties of natural compounds used in popular medicine for gastric ulcers. Brazilian Journal of Medical and Biology Research, 35(5), 523-534. https://doi.org/10.1590/S0100-879X2002000500003

Rice-Evans, C.A., Miller, N.J., Bolwell, P.G., Bramley, P.M. and Pridham, J.B. (1995). The relative antioxidant activity of plant derived polyphenolic flavonoids. Free Radical Research, 22(4), 375-383. https://doi.org/10.3109/10715769509145649

Roberta, R., Pellegrini, N., Proteggente, A., Pannala, A., Yang, M. and Rice-Evans, C. (1999). Antioxidant activity applying an improved ABTS radical. Free Radical Biology and Medicine, 26(9-10), 1231-1237. https://doi.org/10.1016/S0891-5849(98)00315-3

Scheffe, H. (1963). The simplex-centroid design for experiments with mixtures. Journal of the Royal Statistical Society, 25(2), 235-236. https:// doi.org/10.1111/j.2517-6161.1963.tb00506.x

Shahidi, F. and Naczk, M. (1995). Food phenolics: sources, chemistry, effects and applications., p. 287293. Lanchester, Pennsylvania, USA: Technomic Publishing Company.

Sheehata, A.N., Mahmoud, A.E. and Abdou, H.M. (2014). Quantification of total phenolics and total flavonoid contents in extracts of some Egyptian green leaves and estimation of antioxidant activity. Research Journal of Pharmaceutical, Biological and Chemical Sciences, 5(6), 266-273.

Taslimi, P. and Gulcin, I. (2018). Antioxidant and anticholinergic properties of olivetol. Journal of Food Biochemistry, 42(3), 1-12. https:// doi.org/10.1111/jfbc.12516

Velioglu, Y.S., Mazza, G., Gao, L. and Oomah, B.D. (1998). Antioxidant activity and total phenolics in 
selected fruits, vegetables and green products. Journal of Agriculture and Food Chemistry, 46, 4113-4117. https://doi.org/10.1021/jf9801973

Zainol Abidin, N.A., Kormin, F., Mat Salleh, N.S. and Mohamed Anuar, N.A.F. (2018). Development and acceptance of polyherbal formulation for memory enhancement. Journal of Engineering and Applied Sciences , 13(3), 3177-3182.

Zimmerman, H.J. (1999). Hepatoxicity: The adverse effects of drugs and other chemicals on the liver, Philadelphia: Lippincott Williams and Wilkins. 